\title{
A novel strategy for the preparation of naturally occurring phosphocitrate and its partially esterified derivatives
}

\footnotetext{
Petri A. Turhanen ${ }^{*}$, , Konstantinos D. Demadis ${ }^{\ddagger}$, Sirpa Peräniemi ${ }^{\dagger}$ and Jouko J. Vepsäläinen ${ }^{*} \dagger$

${ }^{\dagger}$ University of Kuopio, Department of Chemistry, P.O. Box 1627, FIN-70211, Kuopio, Finland, and Crystal Engineering, Growth and Design Laboratory, Department of Chemistry, University of Crete, Heraklion, Crete, GR-71003, Greece.
}

\section{$\underline{\text { Table of Contents }}$}

General experimental details

${ }^{1} \mathrm{H},{ }^{13} \mathrm{C}$ and ${ }^{31} \mathrm{P}$ NMR spectra of compound 1

${ }^{1} \mathrm{H},{ }^{13} \mathrm{C}$ and ${ }^{31} \mathrm{P}$ NMR spectra of compound $4 \mathrm{a}$

${ }^{1} \mathrm{H}$ NMR spectra of compounds $4 \mathrm{~b}-\mathrm{e}$ and $5 \mathrm{a}-\mathrm{b}$ 
General experimental details: All solvents were dried before use. ${ }^{1} \mathrm{H},{ }^{13} \mathrm{C}$ and ${ }^{31} \mathrm{P}$ NMR spectra were recorded $500 \mathrm{MHz}$ spectrometer operating at 500.1, 202.5 and 125.8 MHz, respectively. TMS or TSP ( $\mathrm{D}_{2} \mathrm{O}$ solutions) were used as an internal standard for ${ }^{1} \mathrm{H}$ and ${ }^{13} \mathrm{C}$ measurements, and $85 \%$ $\mathrm{H}_{3} \mathrm{PO}_{4}$ was used as an external standard for ${ }^{31} \mathrm{P}$ measurements. The ${ }^{3} J_{\mathrm{HH}}$ couplings are indicated by the letter " $J$ ". The ${ }^{\mathrm{n}} J_{\mathrm{HP}}$ couplings were calculated from proton spectra and all $J$ values are given in Hz. The number of protons on each carbon were detected from DEPT-135 experiments and marked after each carbon by the letters s (singlet), d (doublet), $t$ (triplet), q (quartet) or qv (quintet). The ${ }^{n} J_{C P}$ couplings were calculated from carbon spectra with the coupling constants given in parenthesis as hertz. The purity of the products was determined from ${ }^{1} \mathrm{H}$ and ${ }^{31} \mathrm{P}$ NMR spectra and was $\geq 95 \%$ if not stated otherwise. Methylene protons (next to carbonyl groups, ca. $3.3 \mathrm{ppm}$ ) chemical shifts and coupling constants for the compounds 4a-c were calculated using PERCH software. ${ }^{1}$ Electronspray ionization mass spectra were acquired by an LCQ quadrupole ion trap mass spectrometer with an electronspray ionization source (compound $4 \mathbf{e}$ was measured using negative mode). 
哩

\|\|$^{n}$

$$
\text { II }
$$
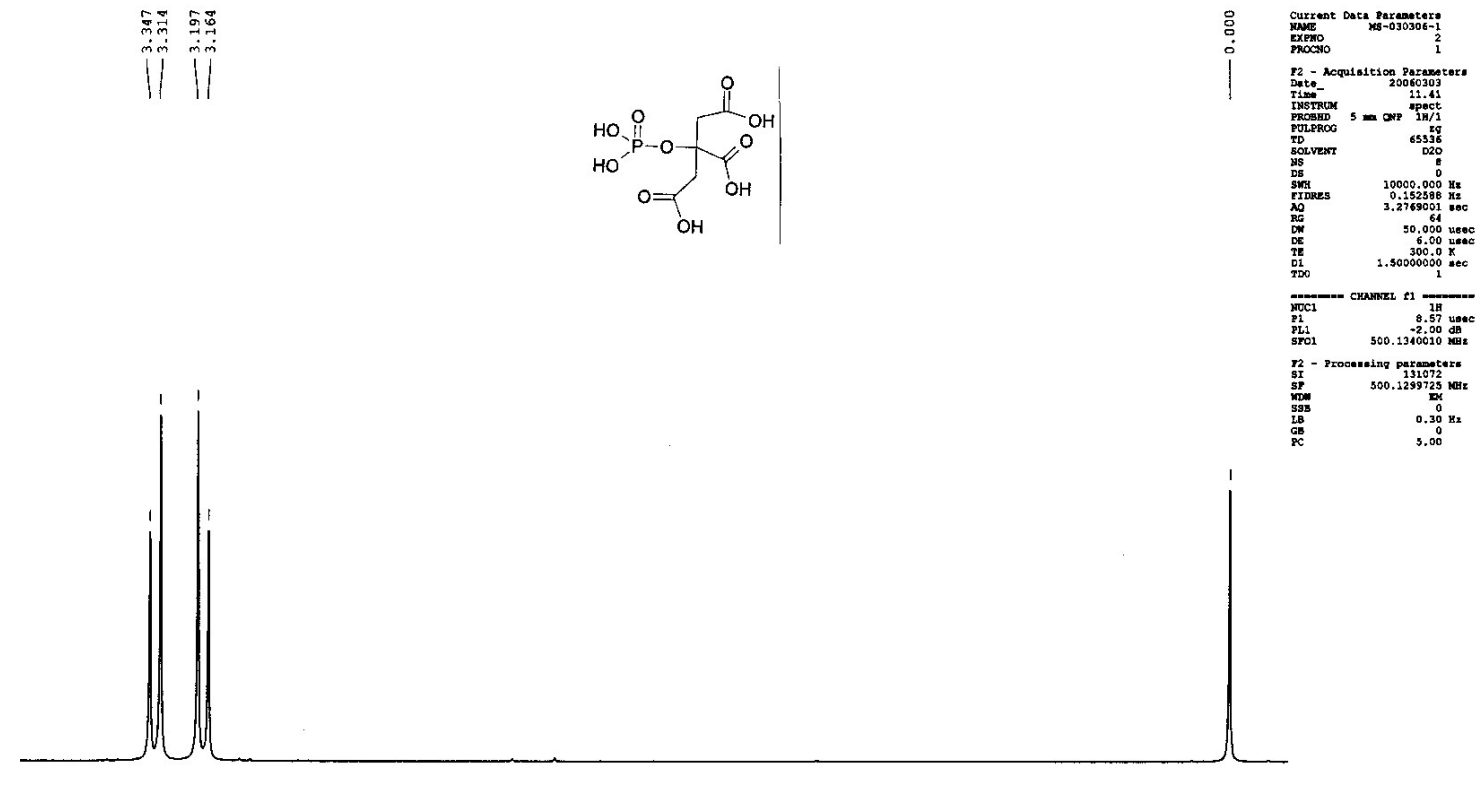

3.5

3.0

2.5

2.0

1.6

1.0

0.5

0.0 ppom

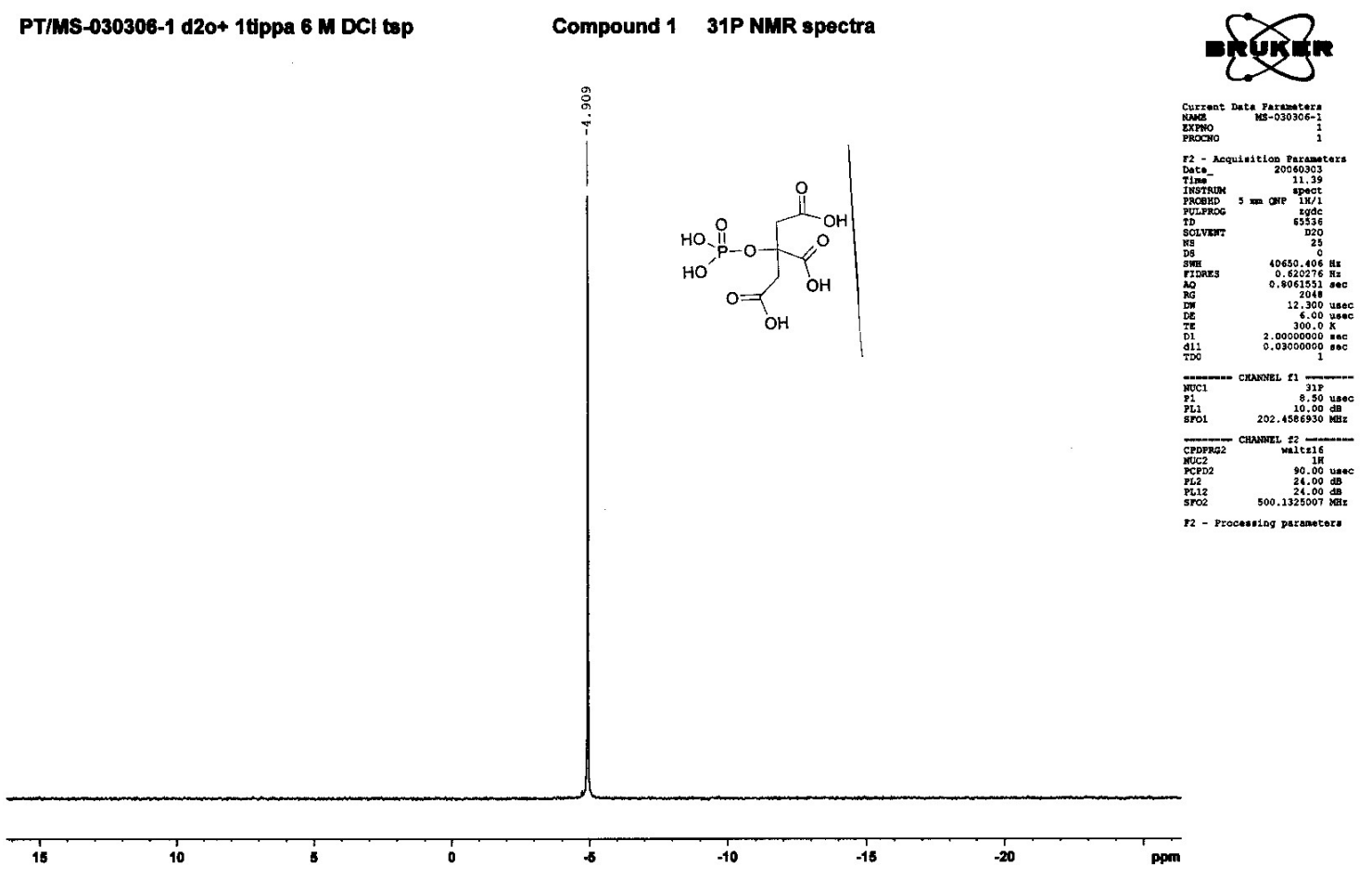


PThMS-030306-1 d20+ 1tippa 6 M DCI tap

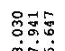

ตำำ

$\sqrt{1}$

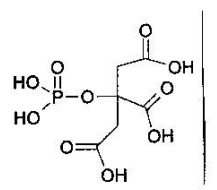

Compound $1 \quad$ 13C NMR spectra

| existo

$\stackrel{5}{5}$

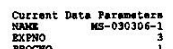

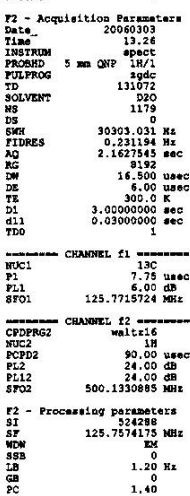

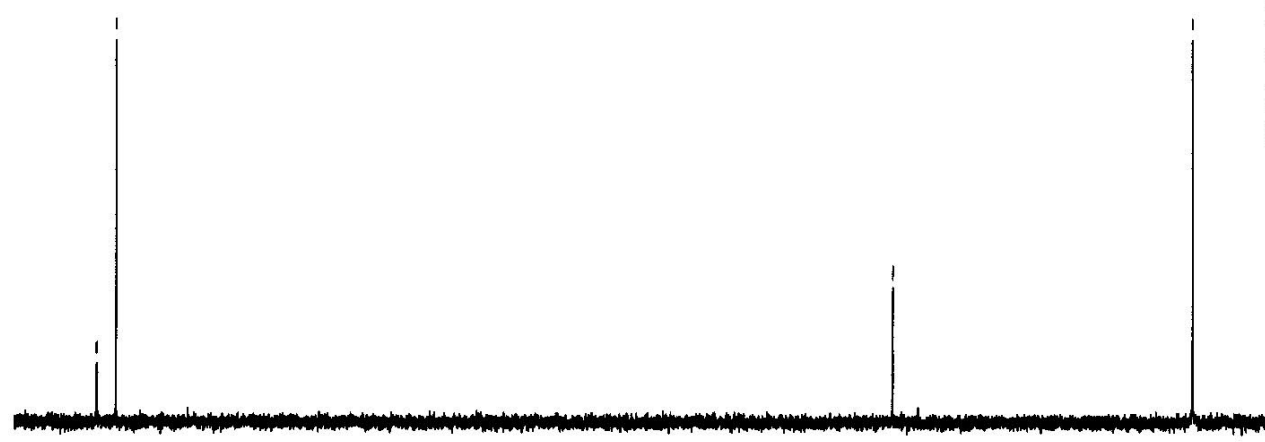

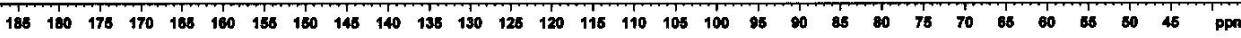

PT/MS-070306-1 cdcl3 tms fr. 23-60
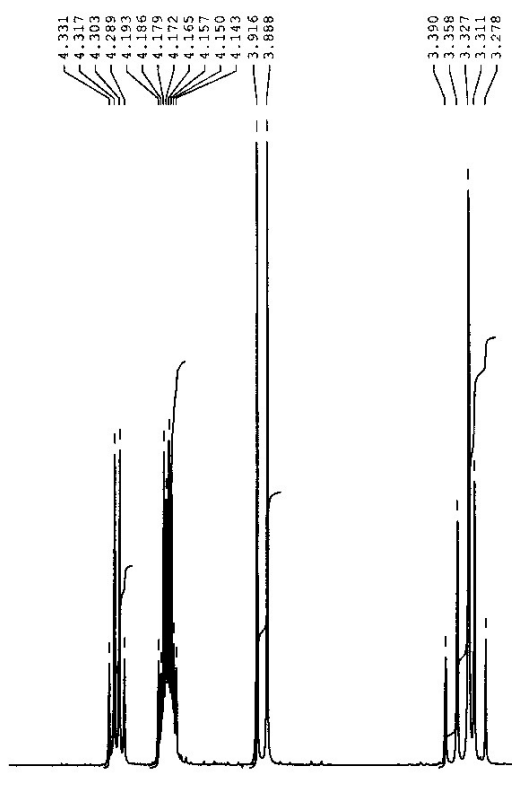

4.6 象影
Compound 4a

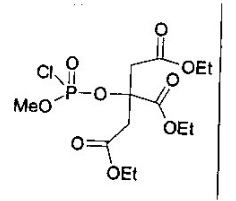

1H NMR spectra

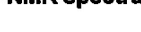

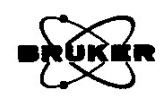

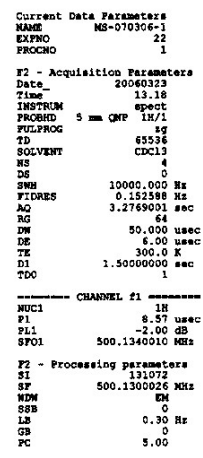



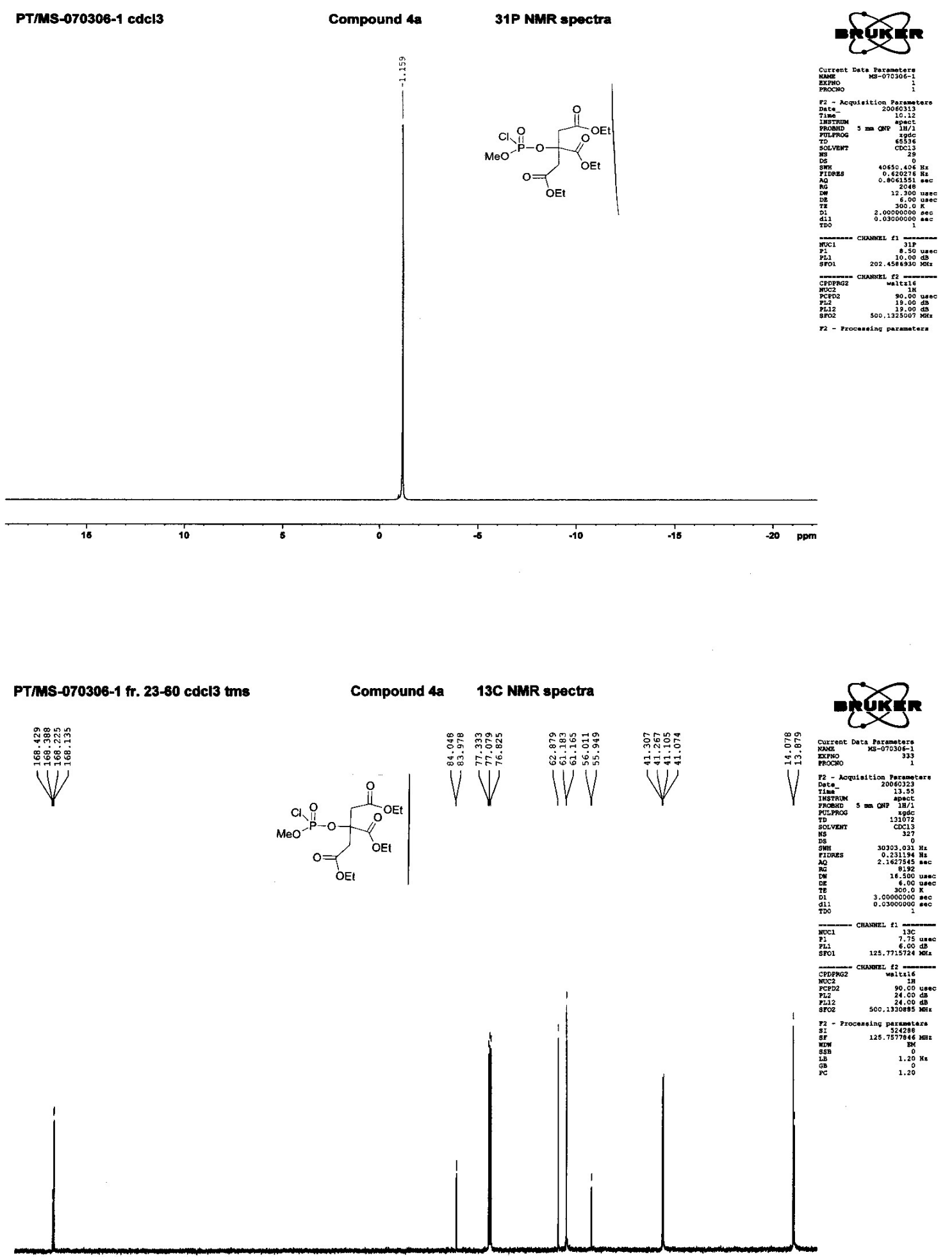

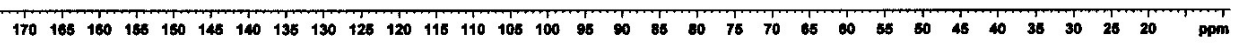



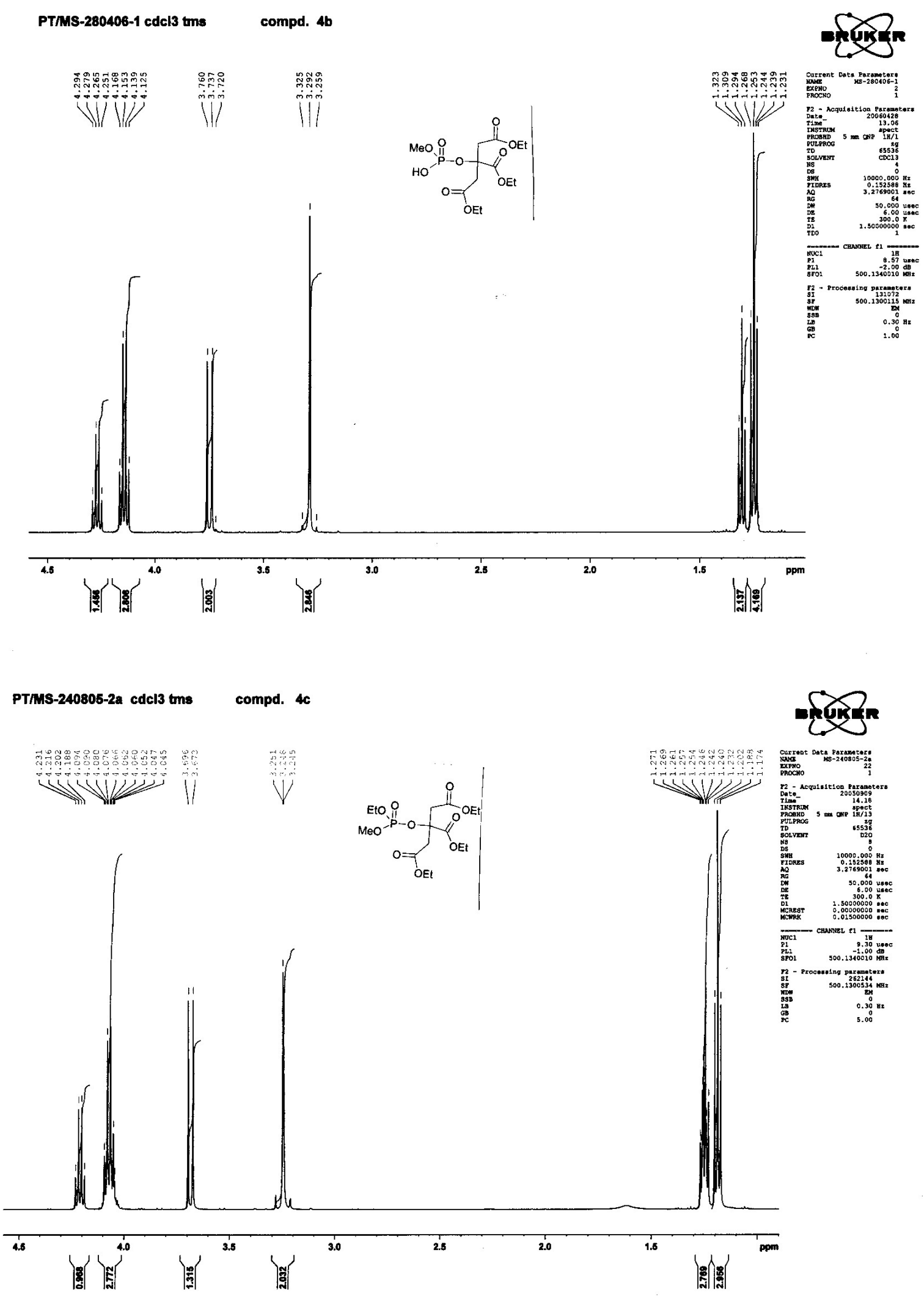


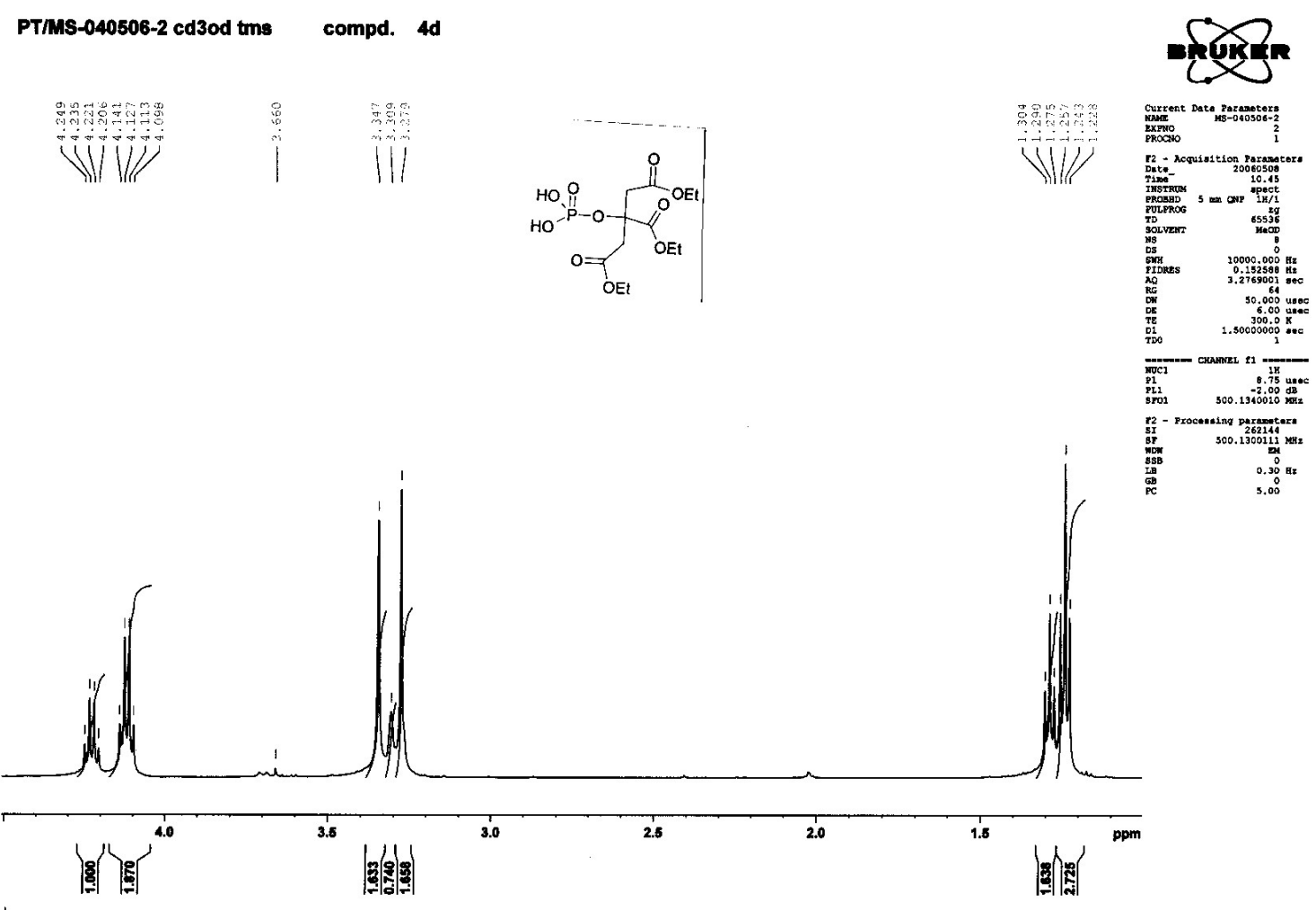

PT/MS-240406-3 cd3od tms compd. 40

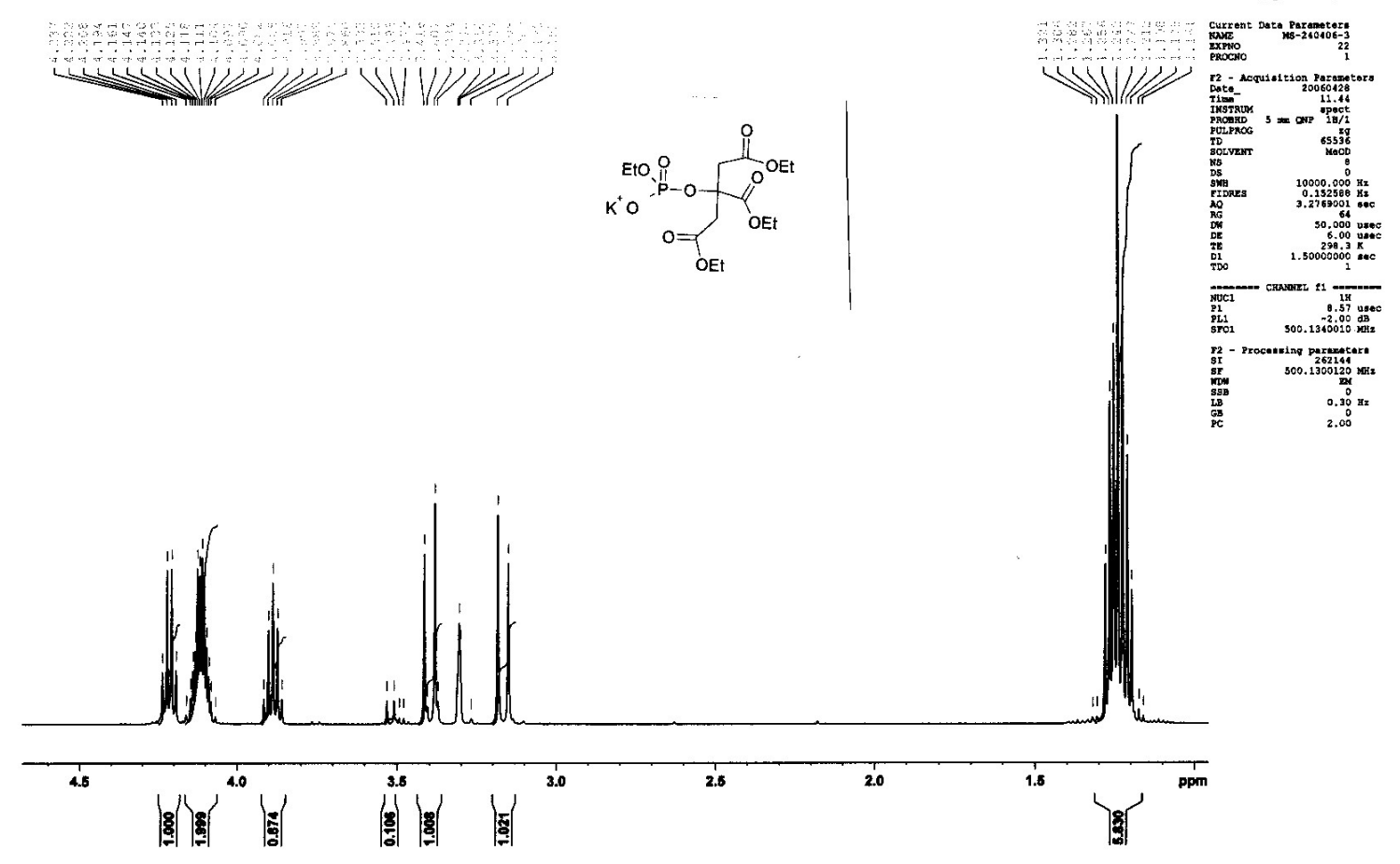



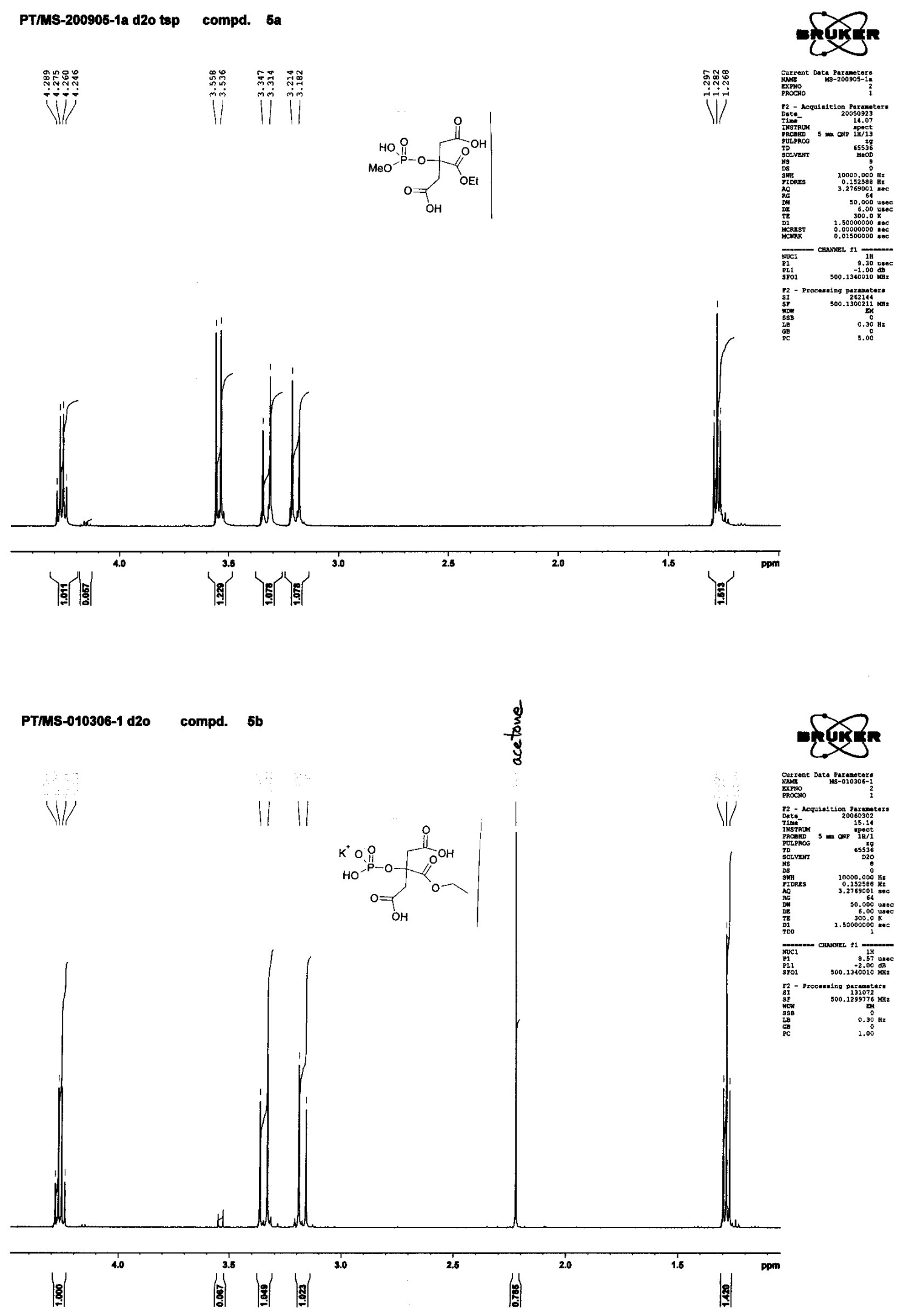
(1) Laatikainen R.; Niemitz M.; Weber U.; Sundelin J.; Hassinen T.; Vepsäläinen J. J. Magn. Reson. 1996, A120, 1. 